\title{
ARTE CONTEMPORÂNEA, PROCESSOS DE CRIAÇÃO E PSICANÁLISE: SAGRADO, AFETOS E SEGREDOS EM ENCONTROS POÉTICOS EXISTENCIAIS
}

\author{
ARTE CONTEMPORÁNEO, PROCESOS DE CREACIÓN Y \\ PSICOANÁLISIS: SAGRADO, AFECTOS Y SECRETOS EN ENCUENTROS \\ POÉTICAS EXISTENCIALES
}

\author{
Nara Salles ${ }^{1}$ \\ Brenda Furtado Pio ${ }^{2}$
}

\begin{abstract}
Resumo: Este artigo versa sobre processos de conexões entre questões que permeiam o que é sagrado, afetos e segredos em encontros poéticos existenciais. Vislumbra-se ainda pensar pedagogias de vivencias poéticas, reminiscências importantes e significativas. Provocamos leituras, desenhos, pinturas, partituras corporais em uma metodologia em que a criação e a poética estejam presentes e sejam identificadas; para que possamos transitar nas questões pertinentes à existência humana, pois o caminho da individuação se dinamiza na coletividade. Propõe-se uma investigação com abordagem qualitativa acerca da saúde mental, loucura e os processos de criação em arte contemporânea utilizando-se do procedimento metodológico criativo intitulado Instaurações Cênicas; aplicado em um grupo de atenção a saúde mental composto por alunos/as da UFPEL e também às pessoas da comunidade externa, enfocando a arte em seus processos criativos em suas variadas expressões e as possíveis relações com a psicanálise em uma perspectiva terapêutica artística e como poética da existência.
\end{abstract}

Palavras-chave: Saúde mental; instauração cênica; psicanálise.

Resumen: Este artículo trata sobre los procesos de conexión entre preguntas que impregnan lo sagrado, los afectos y los secretos en las poéticas existenciales. También se imagina pensar pedagogías de experiencias poéticas, reminiscencias importantes y significativas. Provocamos conferencias, dibujos, pinturas, partituras corporales en una metodología en la que la creación y lo poético están presentes e identificados; para que podamos avanzar en los temas pertinentes a la existencia humana, que el camino de la individualización sea dinámico en la colectividad. Propone una investigación con un enfoque cualitativo de la salud mental, la ubicación y los procesos de creación en el arte contemporáneo utilizando el procedimiento metodológico creativo titulado Instalaciones escénicas; aplicado a un grupo de salud mental por estudiantes de la UFPEL y también a personas de la comunidad externa, enfocándose en el arte en sus procesos creativos en las diversas expresiones y las posibles relaciones con el psicoanálisis en una perspectiva terapéutica artística y poética de existência.

Palabras clave: Salud mental; instauración escénica; psicoanálisis.

Iniciamos o texto com as palavras do Limbiseen $S_{\text {Studio }}^{3}$ : “O espaço cênico é o espaço de todas as possibilidades. É o espaço da liberdade de ser, de sentir, de se expressar... Ambiente acolhedor, um lugar onde o afeto pode circular, o desejo se exteriorizar, o sonho se realizar.

\footnotetext{
${ }^{1}$ Universidade Federal de Pelotas; Universidade Federal do Rio Grande do Norte.

${ }^{2}$ Universidade Federal de Pelotas.

${ }^{3} \mathrm{O}$ Limbiseen é um centro de pesquisa interdisciplinar no qual as emoções, a arte do ator e a eficácia terapêutica do teatro são estudadas através de dispositivos neurocientíficos. O Limbiseen foi idealizado, criado e fundado por Dorys Calvert em 2016.
} 
Venha se emocionar e sonhar com a gente!", pois expressa muito bem aquilo que nos propomos a fazer e nos incita a seguir em tempos tão difíceis.

Este artigo se constitui como o relato inicial de uma pesquisa em andamento, intitulada "Arte Contemporânea, Processos de Criação e Psicanálise: Sagrado, Afetos e Segredos em Encontros Poéticos Existenciais", e está vinculada ao grupo de pesquisas devidamente cadastrado no Diretório de Grupo de Pesquisas do CNPq/Conselho Nacional de Pesquisa, cujo título é "Processos de Criação: Arte e Loucura", e está aprovado e certificado pela Universidade Federal de Pelotas. A pesquisa apresenta abordagem qualitativa e descritiva, focando a pesquisa ação e a clínica ampliada, envolvendo psicanálise e processos de criação em arte contemporânea a partir do procedimento metodológico Instaurações Cênicas (Salles: 2004. P. 181); aplicada em grupos de criação e atenção a saúde mental; enfocando a arte em seus variados processos criativos e as possíveis relações com a psicanálise em uma perspectiva terapêutica artística e como poética da existência. A clínica ampliada, neste caso, também está para além do setting analítico tradicional e busca uma maior implicação das pessoas participantes das ações propostas tirando-as do lugar de doentes e os alçando a novos horizontes e entendimentos de si mesmos em suas potencialidades criativas engendrando vínculos que extrapolam o atendimento em si.

Fundamentamo-nos no argumento de que as obras artísticas são construções poéticas por meio das quais se pode expressar ideias, sentimentos e emoções que resultam do pensar, sentir e fazer, mobilizados pela materialidade da obra, pelo domínio de técnicas, e significados pessoais e culturais. São, por isso, constituídas por um conjunto de procedimentos mentais, materiais e culturais; podendo concretizar-se em imagens verbais, corporais, visuais, sonoras, como manifestações das próprias linguagens em expressão e representação de algo (FERRAZ, 2009 , p. 20). Consideramos extremamente importante discutir quais os canais que conectam os polos do fazer artístico e dos procedimentos acadêmicos, e balizar como estas dinâmicas diversas podem se relacionar. (CARREIRA, 2012, p. 21).

O projeto de pesquisa é desenvolvido no CEART/UFPEL e também prevê instaurações cênicas nas praças e ruas da cidade. Propõe-se um aprofundamento entre arte e psicanálise, pelo viés dos processos criativos presentes no procedimento instauração cênica, procedimento metodológico criativo escolhido para as ações, em si oportunizam expressar as subjetividades, gostos, anseios e desejos, o que pode despertar nas pessoas o entrar em contato com a dimensão afetiva, subjetiva, estética e poética, e assim podemos pensar a arte entrelaçada a psicanálise e como caminho criativo e afetivo para expressões de emoções, sentimentos e entendimentos sobre si mesmo e sobre o mundo, como formas de (re)existir na vida a partir dos corpos restaurados em conexões mente e corpo se apropriando de novos conhecimentos para reconstituírem as imanências em "Um mundo objetivo, em movimento, porque seres humanos o movimentam permanentemente com suas intervenções" Bock (2002). Entendemos que as pessoas são seres com necessidades psíquicas, psicológicas, estéticas e poéticas que precisam encontrar vias para expressá-las, e uma possibilidade pode ser a metodologia da vivência de um processo artístico, com a presença de uma psicanalista e de artistas e pesquisadores/as, alunos e alunas em formação e pessoas da comunidade em geral; como é a proposta de nossa investigação; se constituindo na vivência uma forma não hierárquica, mas permeada pelos afetos (Vide imagem 01 abaixo).

Esta metodologia de trabalho reconhece a importância dos aspectos psíquicos, artísticos e culturais como fatores significativos na construção e estruturação dos possíveis transtornos mentais e que, portanto, respaldam práticas outras, para além da medicamentosa, embora tenhamos a compreensão de que os medicamentos em alguns casos são necessários e devem ser usados com o devido acompanhamento da psiquiatria. Nesta visão de clínica ampliada a arte e a cultura são incluídas como terapêuticas proporcionando uma forma estética e poética da existência para lidar com o sofrimento psíquico, e é neste 
campo que se insere a presente pesquisa, observando que não está sob a ótica de uma terapia dita pura, mas sim focada em uma produção estética e poética, sempre propondo a investigação da memória, a apreciação de obras para fruição e o fazer artístico nos encontros afetivos, poéticos e artísticos; proporcionando vínculos profundos a partir da investigação da esfera dos afetos, suscitando uma poética da existência:

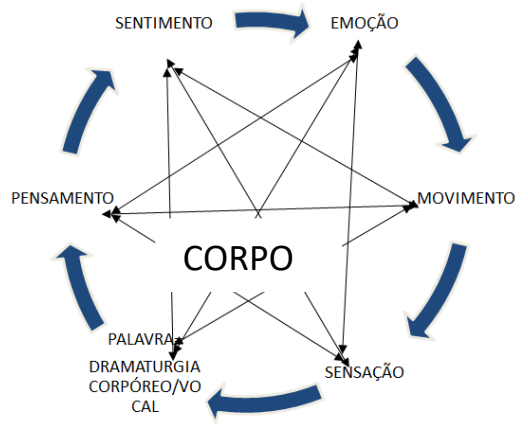

Imagem 01: Esfera dos Afetos

A metodologia, poética e estética proposta nas instaurações cênicas se fundamenta nas obras dos artistas Pedro Almodóvar e Frida Kahlo e dos estudos relacionados a Antonin Artaud, Nise da Silveira, Alfredo Moffatt, Deleuze, Guatarri, Foucault e da primeira autora deste projeto; com o objetivo de realizar instaurações cênicas a partir das escutas em clínica ampliada e com o procedimento criativo Instaurações Cênicas. Utilizamos ainda como referencial teórico os seguintes autores: Françoise Dolto, Fayga Ostrewer, Wassily Kandinsky, Paulo Freire, Vigotski, Gonzalez-Rey, e ainda a vida e obra de Artur Bispo do Rosário, contada por Luciana Hidalgo, que estão sendo extremamente relevantes para as investigações, dialogando diretamente com as histórias de vida e as práticas da cena.

A Instauração Cênica enquanto conceito utilizado como procedimento metodológico criativo para a realização das práticas artísticas presentes nesta pesquisa, é um termo criado pela primeira autora deste artigo em sua tese de doutoramento intitulada "Sentidos: uma instauração cênica - Processos criativos a partir da poética de Antonin Artaud" no Programa de Pós Graduação em Artes Cênicas da UFBA defendida e aprovada no ano de 2004.

A Instauração Cênica proporciona encontros onde a sensibilidade e os sentidos podem ser exacerbados em diversos exercícios cênicos e de leituras, através do estímulo da memória pelos sentidos. A citação a seguir apesar de longa é importante para que possamos compreender o conceito, vejamos,

Instauração é um termo usado pela curadora Lisette Lagnado. Segundo ela, é um dos conceitos fundamentais para a arte contemporânea atual e futura. Para Lagnado foi o artista plástico Tunga quem promoveu o uso do termo instauração, com a obra "Xipófagas Capilares", em 1981, uma obra na qual duas adolescentes se movimentavam unidas por seus cabelos.

O conceito para Lagnado é cunhado a partir dos termos performance e instalação, significando um híbrido destas categorias. A instauração traz e guarda dois momentos: um dinâmico e um estático. De acordo com Lagnado, a acepção de uma instauração supera a característica efêmera da performance, a instauração deixa resíduos, avançando no sentido de perpetuar a memória de uma ação, o que lhe tira o caráter de ser somente uma instalação. Nesta, existe um ambiente montado para determinado acontecimento que pode ser transformado durante o decorrer da ação no ambiente. A instauração não é 
destruída no decorrer da ação, podendo acontecer uma reorganização do ambiente a partir de uma estrutura ou arcabouço estabelecido.

Por este motivo optei por utilizar o termo instauração no título da tese seguido pelo termo cênica, para indicar que naquele local são instauradas ações cênicas e a ambientação não será destruída, mas alterada. Embora utilize para o princípio da montagem, na delimitação do objeto de estudo, os conceitos de performance, não denomino a encenação de "O Jato de Sangue" como performance, porque no meu entendimento, o termo instauração é mais abrangente e a ultrapassa. A performance serve como catalisador deste processo (...) cria-se um espaço que não é destruído durante a apresentação e pode ser observado como obra de artes visuais sem estar acontecendo a encenação, evocando imagens ali instauradas na memória dos espectadores, contemplando, dessa forma, um momento dinâmico e um estático, característica da instauração. Ressalte-se também que a palavra instauração deriva do latim instaurare que significa estabelecer, formar, fundar (SALLES, 2004, p. 181).

De acordo com SOARES (2019, p. 18) compreendendo o conceito de instauração para o paradigma das artes cênicas, ele passa a ser um híbrido que; embora ultrapasse as proposições da performance; transita entre a linguagem da instalação e a da performance, modo pelo qual traz para a cena, respectivamente, o estático e o dinâmico, pois a instauração cênica supera a efemeridade da performance e a contemplação estática da instalação, posto que intenta deixar resíduos nas ações e nos espaços cênicos. Esclarecemos que se começou experimentando a justaposição e interação do teatro e da dança com a música, as artes visuais e o cinema, inspirada na proposta de Antonin Artaud no intuito de buscar uma abrangência maior entre as linguagens artísticas para a prática de cena. $\mathrm{E}$ com o passar dos anos e a continuidade da pesquisa, atualmente, o conceito de instauração Cênica compreende um imbricamento entre todas as artes e inclusive com a moda e nesta pesquisa investiga as possibilidades da intersecção com a psicanálise e a clínica ampliada, aplicada a um grupo de alunos e pessoas da comunidade externa, posto que já foi desenvolvida uma extensa pesquisa com pessoas em internamento por transtornos mentais, na Residência Artística implantada pelo CRUOR Arte Contemporânea e pelo psicólogo Josadaque Albuquerque no Hospital Psiquiátrico Dr. João Machado na cidade de Natal, RN. ${ }^{4}$

A seguir apresentamos o cartaz da chamada para o projeto que teve inicio oficialmente cadastrado e aprovado, em todas as instâncias na UFPEL, em agosto de 2019, portanto trata-se de um projeto em andamento mesmo que tenha sido germinado a partir de agosto do ano de 2018.

\footnotetext{
${ }^{4}$ Vide SILVA, Josadaque Albuquerque da; SALLES, Nara; CEREJEIRA, Jéssica. (Lou)Cure-se!: Uma abordagem Artaudianada da Existência em Instaurações Cênicas no Hospital Psiquiátrico Dr. João Machado. In: CAMINHA, Iraquitan et al. (Org.) Estética e existência, filosofia e loucura. São Paulo: Ed. LiberArs, 2018. SILVA, Josadaque Albuquerque da; SALLES, Nara. Corpos em (re)Existência: A Residência Artística no Hospital Psiquiátrico. In: MARIA NETA, Francisca et al. (Org.). Dinâmicas da resistência: fronteiras, estratégias e mobilizações. Goiânia: Ed Phillos, 2019.
} 


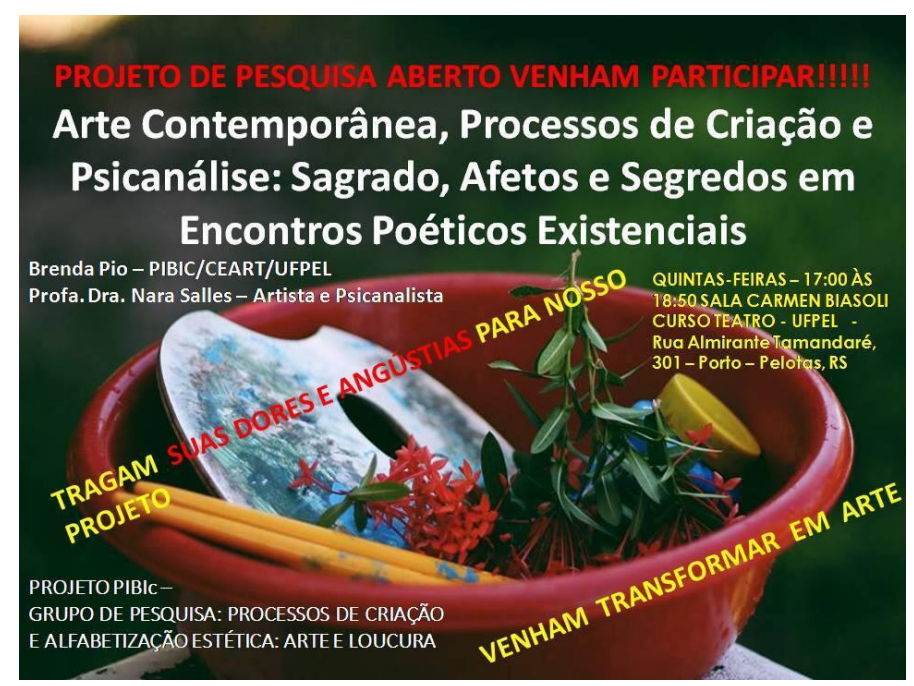

Imagem 02: Cartaz de chamada para o projeto

Estamos promovendo metodologicamente uma ação dialógica entre Instauração Cênica, Psicanálise e Artes, imbuídos na compreensão da dimensão existencial humana, fenômeno complexo que abarca um universo de disciplinas e especificidades no levante de questões sobre o ser humano e suas inquietações no mundo. Entendemos que falar do fenômeno do transtorno mental requer compreensão da dimensão existencial humana e dos processos inconscientes, que são estudados pela psicanálise. Compreendemos que para a construção de conhecimentos sobre o fenômeno da saúde mental no campo da Arte se faz importante uma metodologia em que os encontros, os afetos e os segredos junto as poéticas estejam presentes no trajeto para que possamos transitar nas questões pertinentes a existência humana. Importante destacar que estamos em consonância com Telles (2012); que considera ser uma maneira significativa de problematizarmos uma pesquisa em artes, instalar parâmetros que permitam a análise da criação no contexto da própria criação, ou seja, sem comparações com parâmetros outros que não os próprios determinados pela obra ou processo, o que entendemos como muito relevante para esta pesquisa, e consideramos como uma das metodologias a ser adotada. Nos encontros poéticos existenciais (vide imagens 02, 03, 04 e 05 a seguir) que acontecem na Sala Carmen Biasoli, localizada na Rua Almirante Tamandaré, 301, as quintas feiras a tarde e nos encontros marcados para acontecer em outros horários em variados locais, são aplicadas técnicas relacionadas ao já mencionado, procedimento metodológico de processos de criação intitulado Instaurações Cênicas que lança mão dos recursos criativos da arte contemporânea em seu hibridismo.



Imagem 02: Encontros Poéticos Existenciais: Instaurações Cênicas 
ARTE CONTEMPORÂNEA, PROCESSOS DE CRIAÇÃO E PSICANÁLISE: SAGRADO, AFETOS E...

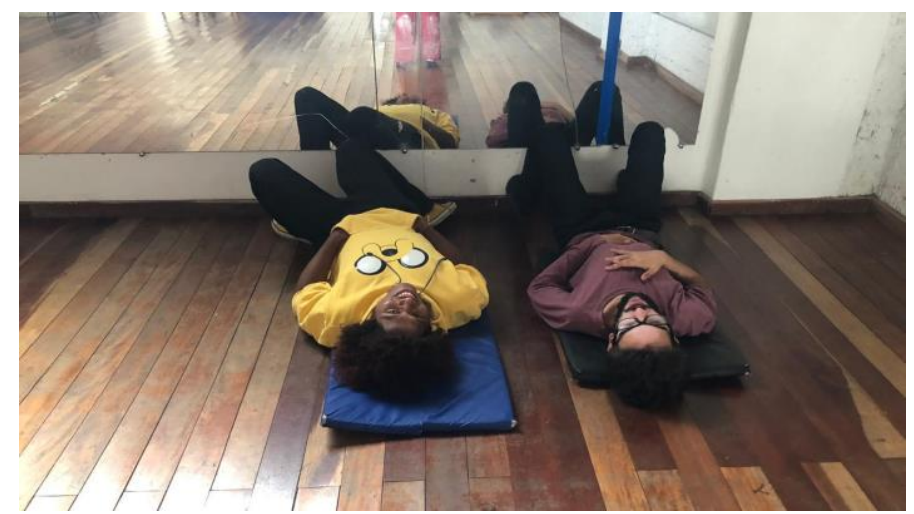

Imagem 03: Encontros Poéticos Existenciais: Instaurações Cênicas

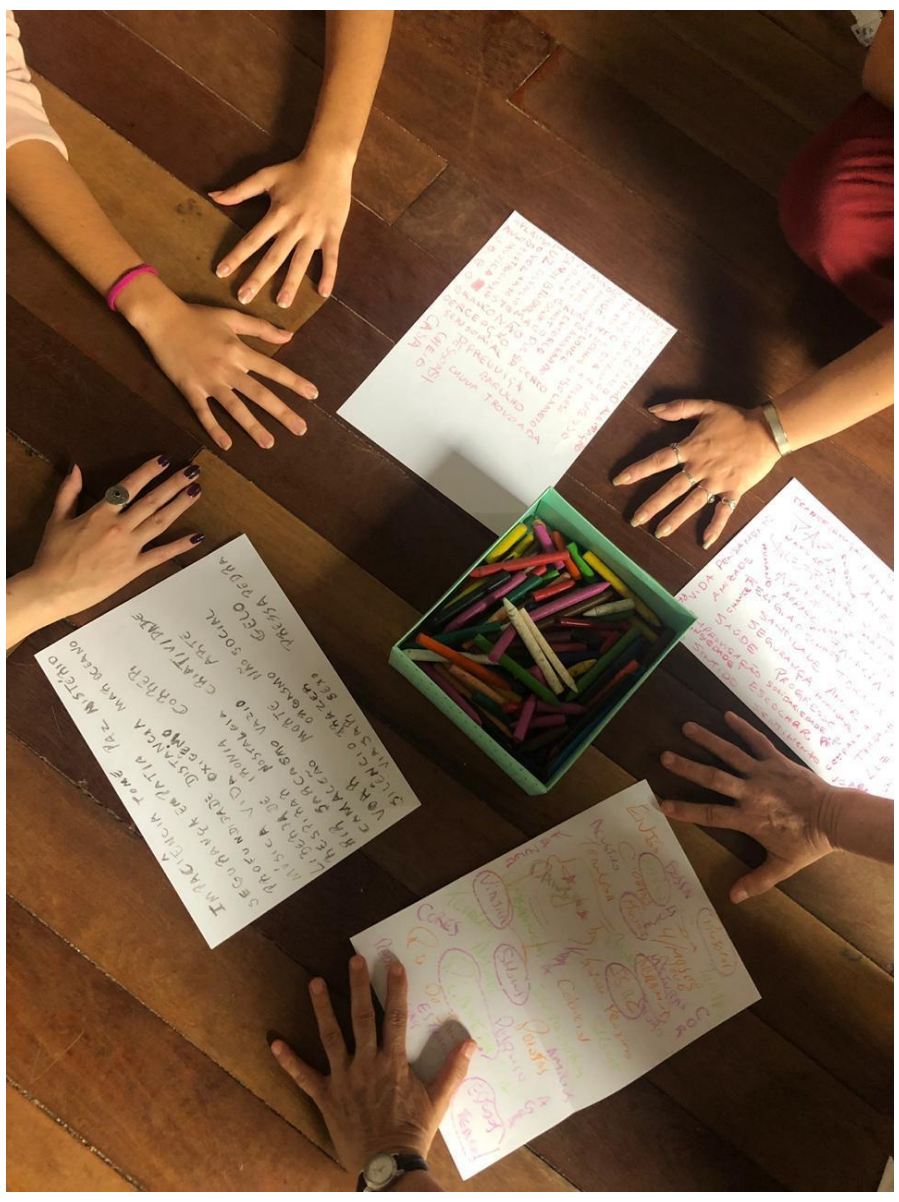

Imagem 04: Encontros Poéticos Existenciais: Instaurações Cênicas 


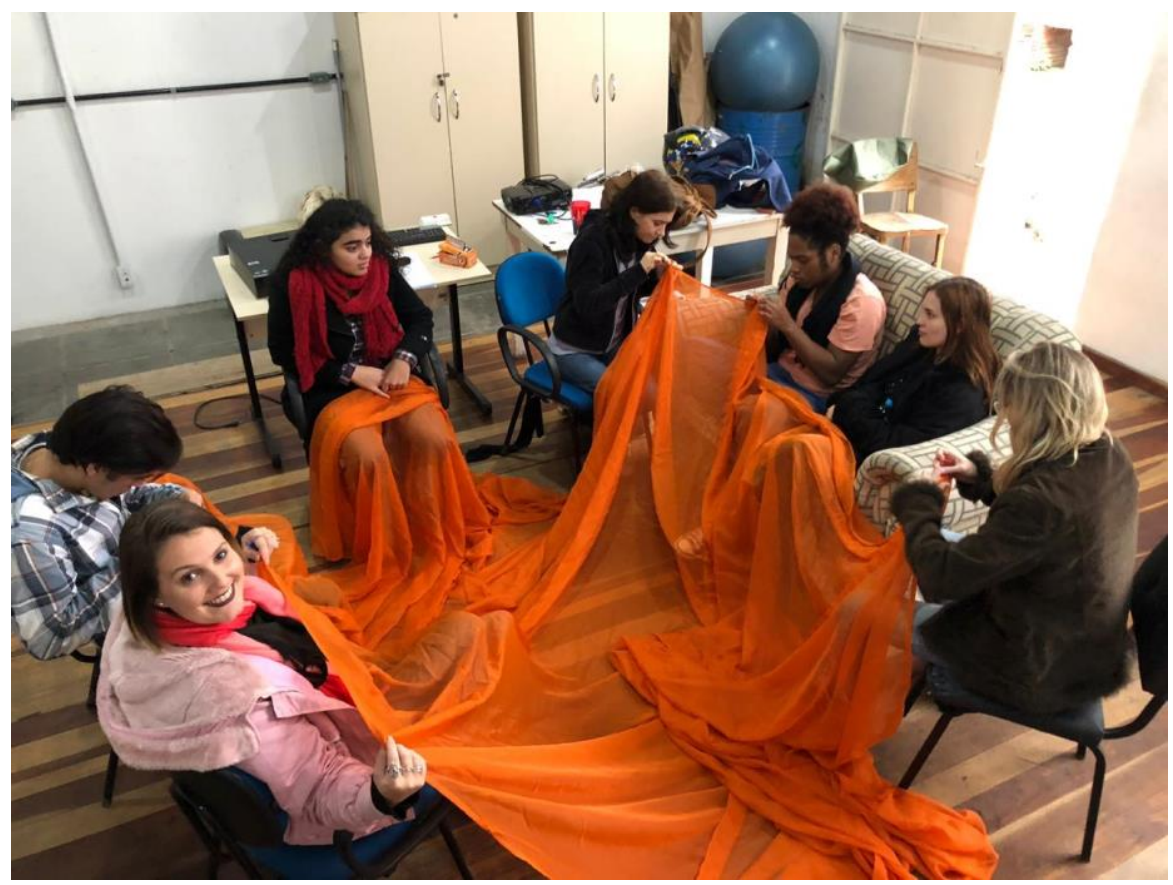

Imagem 05: Encontros Poéticos Existenciais: Instaurações Cênicas

A partir do conceito de representação de Freud, para redescrever as coisas na experiência da psicanálise através da fala, Lacan alia conceitos da fala ao inconsciente, que então é entendido como função simbólica; tendo como suporte a noção de signo ligado ao campo da linguagem como sistema de signos que foi proposto por Ferdinand Saussure, compreendendo signo como algo que representa alguma coisa para alguém, operando significações com outros signos, formando cadeias que são os significantes. Lacan se apropria da linguística e da antropologia estrutural proposta por Claude Levi Strauss de maneira peculiar pois, ele inverte a ordem e afirma ter o significante primazia sobre o significado, sendo a concatenação dos significantes o que determina os efeitos de significado e significante que vai representar o desejo inconsciente se tornando uma lógica de significantes (DUNKER: 2018) que vamos encadeando e desvelando nos processos criativos artísticos.

Os processos criativos em Instaurações Cênicas aliados a uma clínica de escuta ampliada em análise pode vir a cumprir com o papel de introjeção pelos participantes, da função analítica, levando-os a se compreenderem, conviverem e apreenderem a lidar com suas carências, faltas e angústias, na perspectiva de que o objetivo maior de uma análise é proporcionar aos analisandos uma maior compreensão do seu mundo interno e do seu universo psíquico. As pessoas têm procurado o grupo de acolhimento para minimizar, sobretudo sintomas de ansiedade, depressão e disforia, que lhe causam sofrimento e um estreitamento de suas vidas, colocando-os na situação de desvalimento e com o acompanhamento talvez se possa chegar a uma diminuição considerável desses sintomas sinalizando então que o processo poderá ser interrompido.

É interessante pontuar que há uma grande curiosidade acerca de como se constituem esses encontros poéticos afetivos e do que neles acontece, nessa aproximação entre uma artista, psicanalista e antropóloga, uma bolsista de Iniciação Científica, bailarina com outros seres, ávidos por alguma espécie de cura, querendo amenizar sua angústia perante a vida na transformação do sofrimento psíquico. Nossa resposta é que a clínica vai se constituindo com a intervenção da analista/artista e sempre com a implicação sobre o que fazer com o que ouvimos; como sinalizar na atenção flutuante o recordar e repetir para elaborar e como manejar a resistência que por vezes assola os encontros. Está sempre presente em nossa clínica ampliada e criativa a questão de que não 
falar sobre si trás implícito que existe o entendimento de que não se precisa do outro e então não se fala sobre o mundo interno e subjetividades para que um outro não tenha chance de inferir; e neste sentido a transferência psicanalítica e a criação de vínculos é o nosso caminho para que a associação livre aconteça e possamos perceber o desfile de significantes.

E assim nada acontece sem o reflexo das nossas ações no exercício da vida que são faladas na intimidade de cada encontro que é único e sempre sigiloso. E o que dizer da contratransferência? Na terapia pessoal nos trabalhamos para um não afetamento. A diretriz clínica não pode ter expectativas e devemos anular nosso eu na escuta. Tarefa extremamente difícil, e um exercício no cotidiano dos atendimentos e nos encontros poéticos existenciais.

E assim nesse turbilhão de entranhar em si mesmo, ouvir o outro e ir realizando conexões com a teoria, de acordo com o tripé apreendido na formação psicanalítica: análise pessoal, estudos teóricos e prática clínica vão sendo tecidos novos caminhos e novas conexões entre processos de criação, arte e psicanálise.

Concordamos na tessitura desta escrita que, neste ponto se faz importante informar rapidamente e -embora pareça uma digressão nos parece ser importante situar as pessoas que estão a ler-; o lugar de onde falam as autoras e sobre seus desejos por investigar a psicanálise e a arte. A primeira autora deste artigo é artista, psicanalista e antropóloga tendo uma sólida formação acadêmica e no ano de 2012 implantou junto com um dos psicólogos, o Dr. Josadaque Albuquerque, do Hospital Psiquiátrico Dr. João Machado, localizado na cidade de Natal, RN, uma residência artística, fruto de uma pesquisa de mestrado do citado psicólogo sob sua orientação no programa de Pós Graduação em Artes Cênicas da Universidade Federal do Rio Grande do Norte e que teve como desdobramento um projeto de pesquisa sob os auspícios do CNPQ, intitulado "Alfabetização em Arte Contemporânea e Processos de Criação: Investigações Sobre a Loucura”, ligado ao Núcleo Transdisciplinar de Pesquisa em Artes Cênicas e Espetaculares/NACE, (na época sob sua coordenação) e sua coligação de Práticas da Cena CRUOR Arte Contemporânea; devidamente registrado no Grupo de Diretório de Pesquisa do CNPq e que está localizado no Departamento de Artes da UFRN, local onde segue atuando como professora e pesquisadora, nas pós-graduações em artes.

Após ser transferida para a UFPEL seguiu no desejo de ampliar a atuação na área da pesquisa e interfaces entre arte e psicanálise, inclusive continua oferecendo vagas no Mestrado em Artes Cênicas da UFRN para alunos e alunas interessados nessa investigação ao tempo que dá continuidade no percurso pessoal a buscar - se não uma verdade plena, coisa na qual não crê descobertas e aprendizados possíveis e satisfatórios, e que - tal qual na arte, a façam se aproximar do outro em encontros de potência e afetividade. Esse outro que não está em si, mas que ao se fazer presença, se faz importante e a constitui enquanto ser humano para suportar o cruel exercício da vida. Já nos ensinou Antonin Artaud que "não somos livres e o céu ainda pode desabar sobre nossas cabeças" (2006, p. 89) e a experiência da loucura nos comprova este fato.

Quanto a segunda autora é estudante do Curso de Dança Licenciatura da UFPEL e o seu processo dentro do projeto começou com o contato com a sua agora orientadora de iniciação científica, e primeira autora deste artigo, na disciplina do curso de teatro licenciatura com o título Improvisação Teatral II, no ano 2018/2, obtendo mais experiências e técnicas corporais e vocais na área da improvisação, como o próprio título do componente curricular sugere, entrando em contato com o trabalho sobre si mesmo. Como esclarece COPELIOVTCH (2016, p. 76)

Para Stanislavski, a pesquisa em teatro se dá no "si mesmo" do ator. Pesquisar o si mesmo é pesquisar a vida inteira; no caso do teatro, é fazer a vida acontecer na cena. $\mathrm{O}$ acontecimento da vida no palco é o acontecimento desse si mesmo com todas as suas complexidades; é tornar-se linguagem própria à cena. O si mesmo, em constante transformação na impermanência do tempo, 
constitui seu repertório de vivências e revivescências e nos traz questões fundamentais como memória, ação, linguagem e silêncio.

Neste trabalho sobre si mesmo é inevitável que as cicatrizes psíquicas venham a tona e foram surgindo trazendo muita tristeza, e como não havia um ego fortalecido pois em 2017 houve um diagnostico de depressão; sendo que neste período não havia mais o desejo pela vida, somente dormia e chorava, encontrando-se muito fragilizada. Este fato foi relatado à professora tendo inicio um acompanhamento e acolhimento no modelo da clínica ampliada em acompanhamentos de sessões individuais. Inicialmente a professora a buscava no trabalho e havia o tempo de 45 a 60 minutos dedicados a escuta analítica as vezes no carro, ou em algum local escolhido, como por exemplo uma praça, na biblioteca ou em alguma sala disponível no prédio preto da UFPEL. Esse trabalho foi importante para que houvesse uma maior compreensão e descoberta de como poderia lidar com a angústia e conseguir escrever e defender o trabalho de conclusão de curso. Finalmente conseguimos desenvolver um trabalho no LITA/Laboratório Interdisciplinar e Transversal de Artes e nesse período começou a acontecer uma grande procura de alunos e alunas para participar do que iniciava a ser um projeto de pesquisa para cumprir com esta demanda e assim surgiu o grupo de encontros neste local, que contempla a escuta aliada a atividades artísticas. Sendo posteriormente aprovada como bolsista de iniciação científica no referido projeto. Atualmente o local de encontros é a Sala Carmen Biasoli da UFPEL.

Retomando o postulado por Artaud, teremos que ser capazes de retornar a esta idéia superior da poesia pelo teatro, que existe por trás dos mitos e suportar a idéia religiosa e sagrada do teatro. É importante lembrar que as idéias de Antonin Artaud sobre o teatro foram vislumbradas e inspiradas principalmente no teatro oriental balinês, que possui um caráter altamente ritualístico. Ritual pode supor decodificações gestuais, e remete imediatamente a mito, e segundo Claude Lévi-Strauss (1957, p 85):

\begin{abstract}
Postula-se entre mito e rito, uma correspondência ordenada, uma homologia: dos dois qualquer que seja aquele ao qual se atribua o papel original ou de reflexo, mito e rito se reproduzem um ao outro, um no plano da ação, o outro no plano das noções... Se o mito tem um sentido, este não pode se ater aos elementos isolados que entram em sua composição, mas à maneira pela qual estes elementos se encontram combinados.
\end{abstract}

Este fato no olhar de Artaud deveria ser transposto para o teatro e pode ser compreendido, como o princípio do abandono da representação pela presentação ou presentificação do ato cênico. Uma cena onde imagens comuns justapostas e atravessadas, possam provocar e suscitar outras leituras ultrapassando o que é óbvio e evidente, como no caso dos ideogramas chineses isolados. Os que fazem a cena devem vivenciar o ato intensamente, isto é, ao invés de apenas representar, se re(a)presentam. Por exemplo: o ator/dançarino balinês que vive o papel de Rangda ${ }^{5}$ não representa uma feiticeira, ele é uma feiticeira, desde o momento em que começa a se preparar para a encenação e durante o tempo em que se desenrola a história frente aos olhos dos espectadores, que também vivenciam a cena. Estes são arrebatados pelo que ocorre frente a seus olhares e são envolvidos por uma atmosfera mi(s)tica encantatória provocada por uma organicidade corpóreo/vocal dos instauradores da cena. Desta maneira a platéia pode ser tocada em seus recônditos exatamente como acontece em todos os rituais, e este se constitui como um dos princípios da Instauração cênica.

\footnotetext{
${ }^{5}$ Rangda em balinês significa viúva, eles acreditam que se a esposa não acompanha o marido na morte, torna-se uma bruxa má.
} 
Tomamos este exemplo do teatro oriental balinês porque este é importante na obra Artaudiana. Várias vezes, no decorrer de seus textos, Artaud pondera sobre o Oriente, que é um forte referencial ao longo da maioria de seus escritos. No livro O Teatro e Seu Duplo, existe um artigo intitulado "Teatro Oriental e Teatro Ocidental" (1987). No mesmo livro, no artigo "Um Atletismo Afetivo", Artaud utiliza-se do conceito utilizado na medicina chinesa intitulado Yin e Yang. No taoísmo ${ }^{6}$, Yin é o princípio feminino, terrestre, absorvente, frio; com ele coexiste o Yang, que é o princípio masculino, ativo, celeste, penetrante, quente e luminoso. Yin e Yang se configuram como forças ou princípios antagônicos e complementares, que abrangem todos os aspectos e fenômenos da vida. Artaud utiliza-se desta noção de complementaridade entre os opostos, para reforçar a importância e a conexão entre corpo e psiquê no trabalho do atuante. E sob esta perspectiva, Artaud considera que atuadores devem ser atletas do coração, da afetividade, podendo servir-se de suas afetividades da maneira como os atletas e lutadores servem-se de sua musculatura e adverte que a respiração é fundamental neste processo. Em relação a este diálogo de opostos, os escritos de Artaud apresentam um diálogo constante entre o oriente e o ocidente, entre sagrado, inconsciente e crueldade, fato que pretendemos explorar ao longo do desenvolvimento da pesquisa no trabalho corpóreo/vocal e da fala.

Outra característica fundamental da nossa proposta é a transdisciplinaridade, em uma abordagem científica e artística, articulando elementos que passam entre além e através das disciplinas em busca de compreensão das complexidades e produção de novos conhecimentos, compreendida como um diálogo constante entre as variadas formas dos saberes, assim como a busca de um entendimento entre o diálogo interior e exterior dos seres humanos, a teoria e a prática, o sujeito e o objeto (PRADIER, 2000, p. 14), nos processos de criações cênicas.

Importante mencionar que uma das maiores dificuldades em se lidar com a loucura é o fato de que se projeta e se espera de todas as pessoas a organização da vida e gestão de seu tempo da forma que se entende e foi ensinado que é adequado e de acordo com o enquadre imposto pela cultura na qual estamos submersos desde o nascimento; obviamente incluindo neste bojo todas as regras sociais e acordos necessários à boa convivência -e sim algo necessário-; No entanto, ter um comportamento adequado às normas propostas parece ser "a pior parte da doença mental: pois as pessoas esperam que você (o/a louco/a) se comporte como se não a tivesse"; sendo essa uma preocupação e campanha estabelecida pela Associação Potiguar Coletivo Plural $^{7}$ (vide imagem 06); assim sendo toda vez que uma pessoa nestas condições não consegue, por exemplo, acompanhar uma disciplina ou terminar um curso no tempo estipulado para isso acontecer ela é tratada com as mesmas regras que são aplicadas a quem consegue organizar a vida, mesmo que minimamente, para conseguir executar as tarefas e cumprir com regras e acordos. Isto não é possível para quem se encontra em diagnósticos de transtorno mental. Esta pode ser uma dificuldade encontrada por aqueles que vivenciam a experiência da loucura nas escolas formais de ensino. Assim nossa preocupação está voltada a uma sensibilização tanto a professores quanto a gestores sobre esta questão de considerar um tempo mais maleável e de fato estendido nos casos em que se faz necessário compreender outros aspectos que extrapolam o ritmo formal e estabelecido no cumprimento do tempo para conseguir cursar todos os componentes curriculares de um curso e obter aprovação. A questão

\footnotetext{
${ }^{6}$ Sistema religioso e filosófico chinês datado do século IV a.C. Entre as escolas de pensamento de origem chinesa, só o confucionismo superou a influência do Taoísmo. Suas crenças filosóficas e místicas encontram-se no Chuangtzu e no Tao-te Ching (Clássico do Caminho e seu poder, século III a.C.), atribuído a Lao-tsé. O Taoísmo afirma que o indivíduo precisa ignorar os ditames da sociedade e submeter-se, somente, à pauta subjacente ao universo: o Tao (caminho). Para isto deve "fazer nada" (wu-wei), isto é, nada que seja forçado ou anti-natural.

${ }^{7}$ Associação Potiguar Plural é um coletivo de usuários de Serviços de Saúde Mental da cidade de Natal/RN e agrega também familiares, técnicos e defensores dos Direitos Humanos e da Luta Antimanicomial. É um importante pilar de resistência.
} 
que nos norteia no momento é como trabalhar sobre essa ação, posto que a loucura parece aportar em lugares que não comportam o tempo de espera necessário para uma forma de saber lidar com a dissociação, posto que muitas vezes requer terapias de longo prazo associadas a medicações adequadas e na medida certa com acompanhamento psiquiátrico.



Imagem 07 - Campanha nas Redes Sociais da Coletivo Potiguar Plural

E para finalizar devemos insistir na informação de que a pesquisa se encontra no início e ainda não podemos apontar resultados. Está sendo realizada revisão bibliográfica referente ao projeto; e estão sendo aplicados questionários abertos e semi-estruturados com questões surgidas durante os encontros com o grupo de atenção e escuta; relativas a investigação abordada no projeto visando acolhimentos, holding ${ }^{8}$ e processos de criação de Instaurações Cênicas a cada encontro e a serem criadas e apresentadas à comunidade em geral.

\section{Referências}

ARTAUD, A. O Teatro e Seu Duplo. São Paulo: Ed Martins Fontes, 2006.

BOCK, A. M. B. et al. Psicologias. São Paulo: Ed Saraiva. 2002.

CARREIRA. Pesquisa como construção do teatro. In: TELLES, Narciso. Pesquisa em artes cênicas. Rio de Janeiro: E-Papers, 2012.

COPELIOVITCH, A. O Trabalho do Ator Sobre Si Mesmo: Memória, Ação, Linguagem e Silêncio. Concept, Campinas/SP, v. 5, n. 2, jul.-dez. 2016. Disponível em: $<$ https://periodicos.sbu.unicamp.br/ojs/index.php/conce/article/download/8648046/14904?fbcl id=IwAR33noFmWsqgwQwnu7xU16F31PrWr8pJ2UV851J5wcGZFgvZuh6XNvb4Sg8>.

Acesso em: out. 2019.

\footnotetext{
${ }^{8}$ Termo de origem inglesa, provém do verbo inglês To Hold: segurar, manter, ter capacidade para conter, aguentar, resistir. Na psicanálise Winnicott o desenvolve como conceito de sustentação sendo uma das funções da "mãe suficientemente boa", os outros são: handling (manejo) e a apresentação de objetos. Na pesquisa durante as Instaurações Cênicas e sessões desenvolveremos estes conceitos ligados as práticas de investigações dos processos criativos para a cena e teatro como terapia.
} 
DOLTO, F. A Causa das Crianças. São Paulo: Ed. Ideias\&Letras, 2005.

DOR, J. Introdução à leitura de Lacan: O inconsciente estruturado como linguagem. Porto Alegre: Artmed, 1989.

DUNKER, C. Signo Significante e Significado. Falando Nisso, n. 150. Disponível em: <https://youtube/MmXfx0Tztl >. Acessado em: 19/10/2019.

FERRAZ, M. H. C. de T. e FUSARI, M. F. de R. e, Metodologia do ensino da arte. São Paulo: Editora Cortez, 2009.

FOCAULT, M. História da Loucura. São Paulo: Ed. Perspectiva. 1964.

FREUD, S. Obras Psicológicas Completas SIGMUNDO FREUD. Rio de Janeiro: Imago, 1996.

GUATTARI, F; ROLNIK, S. Micropolítica Cartografias do Desejo. Petrópolis: Vozes, 2000.

HIDALGO, L. Artur Bispo do Rosário. São Paulo: Ed. ROCCO, 2011.

LEVI-STRAUSS, Claude. Antropologia Estrutural. Rio de Janeiro: Tempo Brasileiro, 1957.

MEDEIROS, E. E. F. Entre Camadas: Processos de Criação Em Procedimentos de Instaurações Cênicas. Dissertação de Mestrado. PPGARC/UFRN, Natal, 2019.

MOFFATT, A. Psicoterapia do Oprimido. São Paulo: Cortez, 1981.

OSTROWER, F. Criatividade e Processos de Criação. Rio de Janeiro: Vozes, 1997.

PIRES, J. A. S. (Lou)Cure-se! Corpos Vividos em Instaurações Cênicas no H. Psiquiátrico João Machado. Dissertação de Mestrado. PPGARC/UFRN, Natal, 2016.

PRADIER, J. M. Os Estudos Teatrais ou o Deserto Científico. Repertório Teatro e Dança, ano 3, n. 4, PPGAC/UFBA, Salvador, 2000.

SALlES, N. Sentidos: Uma Instauração Cênica. Processos criativos a partir da poética de Antonin Artaud. Tese de Doutorado. PPGAC/UFBA, Salvador, 2004.

SILVEIRA, N. Imagens do Inconsciente. São Paulo: Ed. Vozes, 2015.

TELLES, N. Pesquisa em Artes Cênicas. Rio de Janeiro: 2012.

\section{Sobre as autoras}

Nara Salles é graduada em Artes Plásticas (Universidade Para o Desenvolvimento de Santa Catarina) e Teatro (Universidade Federal de Pernambuco), mestre em Antropologia (Universidade Federal de Pernambuco) e doutora em Artes Cênicas (Universidade Federal da Bahia). Artista e psicanalista. Professora da Universidade Federal de Pelotas e do Mestrado em Artes Cênicas e Mestrado Profissional em Artes da Universidade Federal do Rio Grande do 
Norte. Coordenadora do Grupo de Pesquisa Processos de Criação: Arte e Loucura. Pesquisa Processos Criativos, Instauração Cênica, Antonin Artaud.

E-mail: narasalles@ hotmail.com.

Brenda Furtado Pio é aluna do Curso de Dança da Universidade Federal de Pelotas. Bolsista de Iniciação Científica da Fundação de Amparo à Pesquisa do Estado do Rio Grande do Sul. Professora de Dança e Ludicidade. Desenvolve pesquisas em Ensaio Artístico-Clínico com intervenções Pedagógicas em Dança/Movimento para Crianças e Adolescentes Autistas. Professora de Dança para pessoas com Deficiências Múltiplas.

E-mail: brenda-furtadopio@ hotmail.com. 